\title{
Surveillance endoscopy after ureterosigmoidostomy
}

A 37-year-old woman who underwent a bilateral ureterosigmoidostomy (USS) as a child for bladder exstrophy was scheduled for a surveillance sigmoidoscopy. At $17 \mathrm{~cm}$ from the anal verge, a sharply delineated hyperemic mucosal segment with small dilated vessels was seen ( Fig. 1). Within this segment, an orifice was present where the ureter had been implanted during previous surgery; a pulsatile outflow of clear urine was visi-

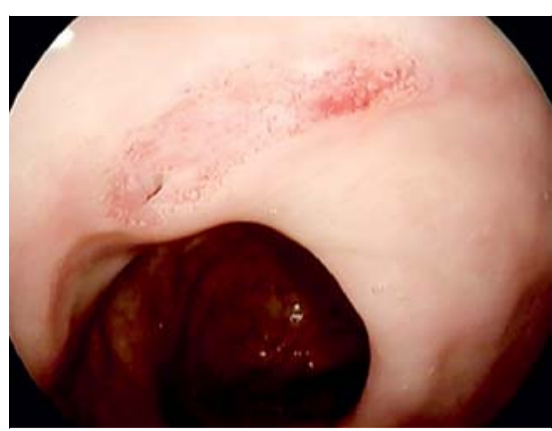

Fig. 1 Endoscopic image of the sigmoid colon showing a sharply delineated hyperemic mucosal segment with small dilated vessels at $17 \mathrm{~cm}$ from the anal verge. Within this segment, an orifice was present where the ureter had been implanted during previous surgery.
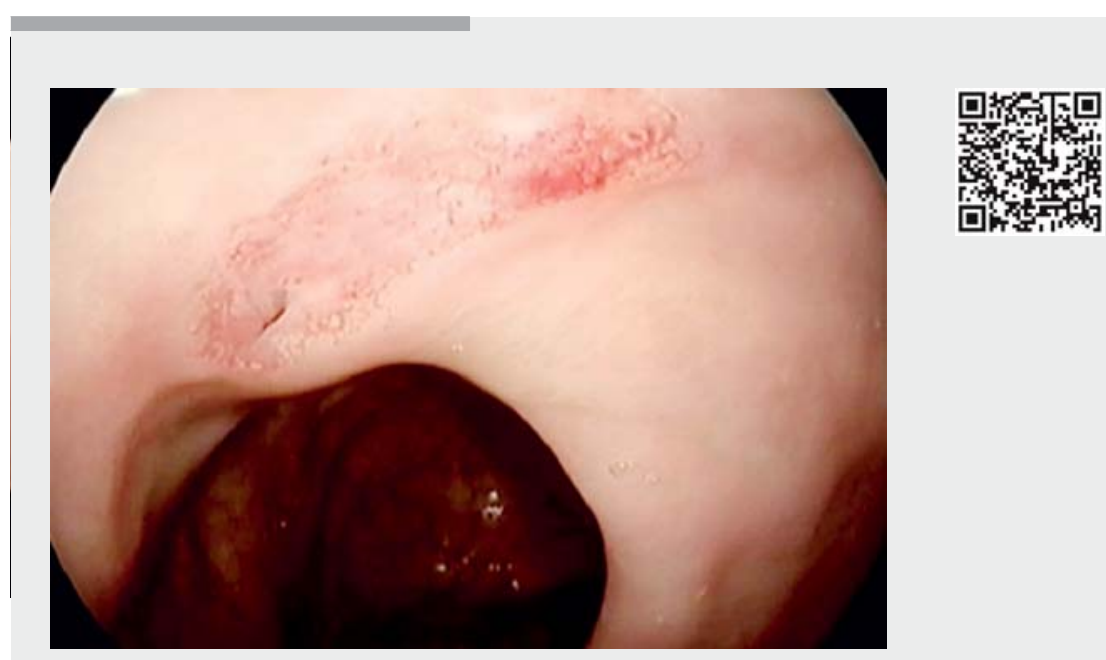

Video 1 Ureterosigmoidostomy with the urethral orifice showing pulsatile outflow of urine into the sigmoid colon. ble ( $\triangleright$ Video $\mathbf{1})$. Targeted biopsies revealed colonic type mucosa with mild fibrosis and an inflammatory infiltrate, but no dysplasia.

USS has long been the most common form of urinary diversion. Colorectal cancer (CRC) risk has been reported to be increased following USS, with a reported incidence as high as $2 \%-15 \%$. The average latency period is $20-26$ years [1]. Cancer usually develops at close proximity to the anastomosis, possibly related to carcinogenic nitrosamine compounds produced by the interaction between urine and native colon flora [2]. Adenomatous changes precede carcinoma development, thus enabling surveillance. Tumors usually display similar immunohistochemical markers as sporadic CRC, but more often show poor differentiation and thus aggressive behavior [3]. Periodic surveillance sigmoidoscopy with random and targeted biopsies is advised to detect early neoplastic changes [4].

Endoscopy_UCTN_Code_CCL_1AD_2AJ

\section{Competing interests}

None

The authors

Matthijs Kramer, Peter D. Siersema, Joost P. H. Drenth

Department of Gastroenterology and Hepatology, Radboud University Medical Center, Nijmegen, The Netherlands

\section{Corresponding author}

\section{Matthijs Kramer, MD, PhD}

Department of Gastroenterology and Hepatology, Radboud University Medical Center, Geert Grooteplein Zuid 10, PO box 9101, 6500 HB Nijmegen, The Netherlands Fax: +31-24-3635129

info@mdl-specialist.nl

\section{References}

[1] Azimuddin K, Khubchandani IT, Stasik JJ et al. Neoplasia after ureterosigmoidostomy. Dis Colon Rectum 1999; 42: 1632 - 1638

[2] Stewart M. Urinary diversion and bowel cancer. Ann R Coll Surg Engl 1986; 68: 98 102

[3] Pettersson L, Tranberg J, Abrahamsson K et al. Half century of followup after ureterosigmoidostomy performed in early childhood. J Urol 2013; 189: 1870-1875

[4] Kalble T, Hofmann I, Riedmiller $\mathrm{H}$ et al. Tumor growth in urinary diversion: a multicenter analysis. Eur Urol 2011; 60: 1081 1086

\section{Bibliography}

DOI https://doi.org/10.1055/a-0885-9381

Published online: 4.6.2019

Endoscopy 2019; 51: E311

(c) Georg Thieme Verlag KG

Stuttgart · New York

ISSN 0013-726X 